\title{
Intracranial Neoplasm
}

National Cancer Institute

\section{Source}

National Cancer Institute. Intracranial Neoplasm. NCI Thesaurus. Code C4953.

A benign or malignant neoplasm that arises from or metastasizes to structures within the cranium. This includes meningeal and other tumors that occur in the spaces that surround the brain, and neoplasms of the brain. 